\title{
CLIL em alemão no Brasil e a competência de leitura dos graduandos em Letras/Alemão
}

\author{
[CLILiG in Brazil and the reading competence of German undergraduate students] \\ http://dx.doi.org/10.11606/1982-8837223848
}

\section{Marina Grilli ${ }^{1}$}

\begin{abstract}
This article discusses a possible role of the Content and Language Integrated Learning in foreign German studies (CLILiG). In Brazil, many students start their undergraduation program without a prior knowledge of German language and it is always a challenge to improve their reading skills in five semesters of language teaching, at least up to B1 level. The empirical research started from the hypothesis that attending CLIL classes can help students to improve their German reading competence. For that matter, the reading competence of GFL students in a Brazilian university was examined. After the categorization of their mistakes, the factors that may have led to the improvement of their reading literacy were defined.
\end{abstract}

Keywords: bilingual education; CLIL; GFL in the university; GFL in Brazil; reading competence.

Resumo: Este artigo discute o papel em potencial do Ensino Integrado de Língua e Conteúdo (CLIL) na graduação em Letras/Alemão. No Brasil, muitos estudantes iniciam a graduação sem conhecimento prévio da língua alemã, e é sempre um desafio melhorar suas habilidades de leitura em cinco semestres de ensino de idiomas, ao menos até o nível B1. A pesquisa empírica parte da hipótese de que frequentar uma disciplina CLIL pode auxiliar os alunos a melhorar sua competência de leitura em alemão. Para tanto, examinou-se a competência de leitura de estudantes de Letras/Alemão em uma universidade brasileira. Após a categorização de seus erros, foram definidos os fatores que podem ter levado à melhoria da alfabetização.

Palavras-chave: ensino bilíngue; CLIL; ensino universitário de ALE; ALE no Brasil; competência de leitura

Zusammenfassung: In diesem Beitrag wird über eine mögliche Rolle des sprachsensiblen Fachunterrichts in ausländischen Germanistikstudiengängen diskutiert. In Brasilien fangen viele Studierende das Lehramtsstudium ohne Vorkenntnisse der deutschen Sprache an und es ist immer eine Herausforderung, ihre Lesekompetenz in fünf Semestern Sprachunterricht zumindest bis Niveau B1 zu fördern. Die Hypothese, von der die empirische Forschung ausgeht, ist, dass es für die Studenten hilfreich sein könnte, an einem CLIL-Seminar teilzunehmen, um ihre Lesefähigkeit zu verbessern. Hierzu wurde die Lesekompetenz von DaF-Studierenden einer brasilianischen Universität untersucht. Nach Kategorisierung ihrer Fehler wurden mögliche Faktoren benannt, die zur Verbesserung der Lesekompetenz geführt haben.

\footnotetext{
${ }^{1}$ Universidade de São Paulo, R. Luciano Gualberto, 403, São Paulo, SP, 05508010, Brasil. E-mail: marina.grilli.silva@usp.br. ORCID: 0000-0002-6324-7030
}

\section{(cc) BY-NC}


GRILLI, M. - CLIL em alemão no Brasil

Stichwörter: bilingualer Sachfachunterricht; CLIL; DaF im universitären Kontext; DaF in Brasilien; Lesekompetenz.

\section{Introdução}

Este trabalho tem como foco o ensino de alemão em contexto universitário no Brasil, e une três polos: o ensino de alemão como $\mathrm{L}^{2}$, o ensino universitário de alemão e o ensino integrado de língua e conteúdo (CLIL).

Os relatos de pesquisas de $\mathrm{DaF}$ no Brasil têm crescido nas últimas décadas (ARAÚJO; UPHOFF 2017). À medida que ganham destaque as especificidades do ensino de alemão nas universidades brasileiras, são evidenciados também os problemas a elas relacionados, como o baixo conhecimento de línguas estrangeiras devido à precariedade do ensino público em todo o país e a falsa ideia de que um curso de Letras é uma espécie de curso de LE.

A partir desse cenário, pretende-se aqui participar da investigação dos fatores que influenciam no desenvolvimento dos graduandos em Letras/Alemão no que concerne às competências na língua-alvo, sobretudo à competência de leitura, tão fundamental para o estudante de Letras e para o futuro professor quanto para o cidadão do mundo na era pósmoderna. A hipótese que deu origem ao estudo é a de que frequentar uma disciplina CLIL durante a graduação em Letras/Alemão pode contribuir para o desenvolvimento da competência de leitura dos graduandos.

Königs (2013: 37-38) afirma que já se sabe bastante sobre o CLIL na Alemanha e em diversos outros países europeus, e agora é necessário conhecer pesquisas a respeito em outros países: em escolas bilíngues, em sistemas de ensino escolar inseridos em sociedades multilíngues e em universidades que oferecem cursos em LE. De acordo com o mesmo autor (KöNIGS 2013: 34), ainda não é discutido amplamente se e como a modalidade CLIL pode contribuir para o estímulo da língua em que o aluno tem competências menos desenvolvidas.

No Brasil, as pesquisas na área do CLIL costumam focar no inglês ou no espanhol como língua estrangeira, já que a oferta do ensino bilíngue envolvendo essas línguas é muito mais ampla do que a oferta do ensino português-alemão, mesmo em escolas privadas. Quatro trabalhos brasileiros da última década sobre o CLIL são: a dissertação

\footnotetext{
${ }^{2}$ L3 significa aqui a terceira língua ou segunda língua estrangeira aprendida por um falante; da mesma forma, L2 se refere à segunda língua ou à primeira língua estrangeira de um falante.
} 
GRILLI, M. - CLIL em alemão no Brasil

de mestrado de Moura (2009), que analisa uma sala de aula de $1^{\circ}$ ano do Ensino Fundamental em uma escola bilíngue de prestígio; a dissertação de mestrado de Guimarães (2015) sobre o planejamento CLIL por tarefas na aprendizagem de espanhol em um curso técnico; os trabalhos de Leão \& Finardi (2014) e Casotti \& Finardi (2016), que se ocupam, respectivamente, da elaboração de atividades CLIL para o ensino de Ciências por meio do inglês e do uso da abordagem CLIL na formação de professores de línguas.

Em resumo, a abordagem CLIL é um vasto campo a ser explorado, e seus efeitos sobre a aprendizagem de língua são objeto de pesquisa com menor frequência do que seus efeitos sobre a aprendizagem do conteúdo. Neste trabalho, procuramos investigar justamente os efeitos da abordagem CLIL sobre a aprendizagem de língua.

\section{Um panorama da aprendizagem de língua estrangeira no Brasil}

O inglês ainda é aprendido como L2 na maior parte dos países do mundo, e como L3 em países onde a maior parte da população já é bilíngue. No Brasil, não é diferente: a primeira LE mais comumente aprendida no ensino obrigatório é o inglês, embora sua obrigatoriedade não constasse na lei até 2016, mas sim "o ensino de pelo menos uma língua estrangeira moderna" à escolha da comunidade escolar (BRASIL 1996). De qualquer forma, o ensino de LE só é obrigatório a partir do sexto ano, quando os alunos já têm por volta de 11 anos de idade, e a oferta da segunda LE - preferencialmente o espanhol - só tem início quatro anos depois, e em caráter optativo (BRASIL 1996). Isso significa que os estudantes brasileiros ingressam na universidade com pouco conhecimento de línguas estrangeiras, a não ser que tenham tido a oportunidade de frequentar cursos livres fora da escola.

Não só no que concerne a línguas, mas o sistema educacional brasileiro como um todo apresenta grandes falhas: dentre os 70 países e economias que participaram do Programa Internacional de Avaliação de Aluno (PISA) de 2015, o país conquistou a posição de número 59 em leitura, 63 em ciências e 65 em matemática (ORGANIZAÇÃO PARA A COOPERAÇÃO E DESENVOLVIMENTO ECONÔMICO, 2016). Somandose a isso o abismo entre a qualidade do ensino público e do ensino privado, devido à grande desigualdade social no país, o desempenho dos alunos de escolas públicas é ainda pior. Com base nesses problemas, pode-se imaginar o quão precário é o ensino de LEs 
GRILLI, M. - CLIL em alemão no Brasil

nas escolas brasileiras: dentre a população de 16 anos ou mais, somente 5,1\% afirmam possuir algum conhecimento do inglês; dentre os jovens de 18 a 24 anos, o número dobra, chegando a somente 10,3\% (BRITISH COUNCIL 2014: 7).

Esse cenário fornece uma perspectiva do quão restrito é o acesso à língua alemã no Brasil. O número de aprendizes de ALE na América Latina aumentou, segundo pesquisa de 2015 (AUSWÄRTIGES AMT). No Brasil, havia 30\% mais aprendizes de alemão em 2015 do que em 2010. Entretanto, a quantidade deles na América Latina ainda corresponde a menos de $1 \%$ dos alunos matriculados em escolas. E se o acesso a cursos de língua alemã no Brasil já é privilégio de poucos, o contato com a aula CLIL em língua alemã é ainda mais raro.

\section{$3 \bigcirc$ contexto universitário}

O contato com a aula CLIL em língua alemã no Brasil é encontrado, majoritariamente, em dois contextos: em colégios bilíngues privados, concentrados em uma área reduzida do país e acessíveis apenas à pequena parcela da população que pode custear o elevado valor das mensalidades, e em universidades públicas que oferecem cursos de Bacharelado ou Licenciatura em Letras com habilitação em Alemão. Escolas em regiões de imigração, onde se fala e ensina o alemão padrão e/ou uma variante regional da língua e se oferece conteúdo disciplinar parcialmente bilíngue, são minoria no país e situam-se quase que exclusivamente na região Sul (cf. FRITZEN 2007, 2013; SPINASSÉ 2005; 2006).

No contexto universitário brasileiro, mais especificamente nos cursos de Letras/Alemão, ambiente em que consiste o foco deste trabalho, o ensino do alemão costuma iniciar no nível A1. Isto significa que saber a língua não é pré-requisito para entrar em 16 das 17 universidades que oferecem cursos de Bacharelado ou Licenciatura em Letras com habilitação em Alemão. Desse modo, de acordo com Blume (2011: 54), grande parte do currículo fica comprometida com o ensino da língua, mas os futuros professores não atingem um nível suficiente de domínio dessa língua; é "como se um graduando de matemática tivesse de aprender a tabuada na faculdade".

Mesmo assim, não se pode generalizar os cursos de Letras como se houvesse uma estrutura homogênea por trás de todos eles: Evangelista (2011) e Blume (2011: 54) afirmam que a divisão das disciplinas varia muito de uma universidade para outra, tanto nas relacionadas a língua e literatura - laboratório [Sprachlabor]; conversação; 
GRILLI, M. - CLIL em alemão no Brasil

introdução à linguística; produção de textos em alemão; literatura alemã traduzida quanto nas disciplinas da área de didática, cultura e tradução. Bolacio Filho \& Moura (2014: 83) afirmam ser de conhecimento comum que "o bacharelado em Letras é na maioria das faculdades no Brasil caracterizado pela falta de um perfil claro".

A tabela abaixo lista as universidades onde é possível cursar Letras/Alemão no Brasil, com habilitação em Português e Alemão ou somente em Alemão, concentradas por região do país.

\begin{tabular}{|c|c|c|c|c|c|c|}
\hline \multicolumn{7}{|c|}{ Cursos de Letras/ Alemão no Brasil } \\
\hline & Licenciatura & Bacharelado & $\begin{array}{c}\text { Licenciatura/ } \\
\text { Bacharelado }\end{array}$ & $\begin{array}{c}\text { Português/ } \\
\text { Alemão }\end{array}$ & $\begin{array}{c}\text { somente } \\
\text { Alemão }\end{array}$ & ênfase \\
\hline UFPA & $\mathrm{X}$ & & & & $\mathrm{X}$ & \\
\hline UFC & $\mathrm{X}$ & & & $\mathrm{X}$ & & \\
\hline UFBA & $\mathrm{X}$ & $\mathrm{X}$ & & $\mathrm{X}$ & $\mathrm{X}$ & \\
\hline UFMG & $\mathrm{X}$ & $\mathrm{X}$ & & $\mathrm{X}$ & & $\mathrm{X}$ \\
\hline UFF & $\mathrm{X}$ & $\mathrm{X}$ & & $\mathrm{X}$ & $\mathrm{X}$ & \\
\hline UFRJ & $\mathrm{X}$ & $\mathrm{X}$ & & $\mathrm{X}$ & & \\
\hline UERJ & $\mathrm{X}$ & $\mathrm{X}$ & & $\mathrm{X}$ & & \\
\hline USP & $\mathrm{X}$ & $\mathrm{X}$ & $\mathrm{X}$ & $\mathrm{X}$ & $\mathrm{X}$ & \\
\hline UNESP Assis & $\mathrm{X}$ & & & $\mathrm{X}$ & & \\
\hline UNESP Araraquara & $\mathrm{X}$ & $\mathrm{X}$ & $\mathrm{X}$ & $\mathrm{X}$ & & \\
\hline UFPR & $\mathrm{X}$ & $\mathrm{X}$ & & $\mathrm{X}$ & $\mathrm{X}$ & $\mathrm{X}$ \\
\hline UNIOESTE & $\mathrm{X}$ & & & $\mathrm{X}$ & & \\
\hline UFSC & $\mathrm{X}$ & $\mathrm{X}$ & & & $\mathrm{X}$ & \\
\hline UFRGS & $\mathrm{X}$ & $\mathrm{X}$ & & $\mathrm{X}$ & $\mathrm{X}$ & \\
\hline ISEI & $\mathrm{X}$ & & & $\mathrm{X}$ & & \\
\hline UFPEL & $\mathrm{X}$ & & & $\mathrm{X}$ & & \\
\hline FURB & $\mathrm{X}$ & & & & $\mathrm{X}$ & \\
\hline Tata UnIVES
\end{tabular}

Tabela 1. Universidades brasileiras que oferecem a graduação em Letras/Alemão e seus modelos de curso, elaborada pela autora

Na USP, foi realizado um estudo sobre a realidade dos alunos do bacharelado em Letras/Alemão durante a chamada "passagem" das aulas de língua para as de literatura (UPHOFF; DEBIA 2017), em que a maioria dos participantes informou ter conhecimento do alemão entre os níveis A2 e B1 no semestre de início das aulas de literatura alemã. Entretanto, conforme apontam as autoras (UPHOFF; DEBIA 2017: 173-4), o próprio Quadro Europeu Comum coloca a leitura de textos literários como competência esperada a partir do nível B2, e a escrita de resumos e resenhas de obras literárias somente no nível C2. Esse dado fornece uma dimensão das dificuldades que os alunos enfrentam ao ter que 
GRILLI, M. - CLIL em alemão no Brasil

cursar disciplinas de conteúdo em alemão após cursar apenas cinco semestres de aulas de língua.

De fato, o baixo nível de conhecimento do alemão a que chegam os alunos universitários durante o curso costuma não ser suficiente para acompanhar, de forma adequada, as disciplinas de "conteúdo", isto é, de literatura e cultura alemã: a maior parte dos participantes do estudo relatado por Uphoff \& Debia (2017: 178) afirmou considerar razoáveis suas competências de compreensão oral e escrita, mas insuficientes para trabalhar com textos acadêmicos.

Desse modo, é notável a dificuldade de chegar a um consenso quanto às medidas que deveriam ser tomadas para reduzir as disparidades, tanto entre os currículos quanto entre expectativa e realidade do profissional formado por esses cursos. Enquanto alguns criticam o fato de a graduação em Letras/Alemão ser percebida como curso de língua (Blume 2011; UPHOFF, LOBATO \& SAFRA 2014), outros apontam uma carga horária maior de aulas de língua (EVANGELISTA 2011) como solução para aumentar a qualidade da formação. A modalidade CLIL pode ser uma sugestão válida para diminuir a discrepância entre o que o estudante sabe e o que o profissional deveria saber. A próxima seção se ocupa da modalidade CLIL.

\section{A aula CLIL}

Desde o início do século XXI, o Ensino Integrado de Língua e Conteúdo tem se consolidado como parte do sistema de ensino europeu. Hoje, é conhecido no âmbito europeu através das siglas CLIL e EMILE [Enseignement d'une Matière Intégré à une Langue Étrangère]. Às vezes considerados como sinônimos, e outras vezes como ideias ligeiramente divergentes entre si, os termos podem ser diferenciados de acordo com a organização do insumo bilíngue ofertado, com a função e os objetivos do uso da LE e com os conceitos didáticos que os embasam (SCHMELTER 2013: 43). No Brasil, o termo "aula bilíngue" também é utilizado com frequência para designar uma aula conforme os parâmetros do CLIL.

Um princípio comum a todos os ambientes CLIL é a busca por um universo de aprendizagem e vivência na língua-alvo, no qual, além da aquisição do conhecimento formal sobre a língua, haja oportunidades de usar a linguagem técnica geral e específica da disciplina ou área do conhecimento envolvida (HAATAJA \& WICKE 2016: 4). 
GRILLI, M. - CLIL em alemão no Brasil

Segundo Rösler (2010: 13), as características fundamentais de uma aula dentro dos parâmetros do CLIL são as seguintes:

- Consciência (awareness) do professor acerca de sua linguagem, para que os alunos menos proficientes não sejam prejudicados na compreensão do conteúdo;

- Code-switching do professor para checar a compreensão de novos conceitos;

- Uso de suporte visual para que os alunos acompanhem o roteiro da aula, isto é, roteiro por escrito em handouts ou slides;

- Nem o professor nem os alunos devem discriminar o colega que deseja usar a L1 em sala de aula, pois a prioridade é a compreensão do conteúdo.

Percebe-se o quanto o trabalho com a abordagem CLIL exige dos professores que o abraçam. Marsh et al. (2005: 16-27) apresentam uma longa lista de habilidades esperadas do professor CLIL no que concerne ao comprometimento com o próprio desenvolvimento pessoal, ao conhecimento dos fundamentos do CLIL, à consciência acerca da língua e do conteúdo, ao conhecimento dos recursos necessários para fomentar as capacidades do aluno e cooperar com os demais professores, às formas de avaliar, entre outras habilidades.

Leão \& Finardi (2014) observam ainda que o CLIL está de acordo com o conceito de ensino proposto por Paulo Freire, na medida em que este afirma que "ensinar não é transferir conhecimento, mas criar as possibilidades para a sua produção ou a sua construção" (FREIRE 1996: 24). Segundo as autoras, esse princípio se relaciona à abordagem CLIL porque ela é capaz de despertar criatividade e interesse nos aprendizes, a fim de que eles possam usar a língua de forma crítica e autônoma (LEÃo \& FINARDI 2014).

De acordo com Mello (2010: 119-120), existem muitas nomenclaturas e termos para designar os diversos modelos de educação bilíngue, e esses modelos podem chegar a enquadrar-se em mais de uma nomenclatura. No âmbito do ensino escolar, a autora (MELlo 2010: 120-21) distingue majoritariamente entre a educação bilíngue transicional e a educação bilíngue de manutenção, sendo a primeira aquela em que a instrução na L1 do aluno acontece somente até que a criança consiga acompanhar as aulas em L2, e a segunda, a que busca preservar o contato do aluno com sua L1 no ambiente escolar.

Tratando especificamente do ensino de ALE, Haataja \& Wicke (2016) diferenciam as seguintes variantes de aplicação da abordagem CLIL: 
GRILLI, M. - CLIL em alemão no Brasil

- A aula de língua que abrange conteúdo disciplinar [fächerübergreifender Deutsch als Fremdsprache-Unterricht], indo além do conteúdo disciplinar específico e assumindo a função de apresentar os recursos necessários em LE para tornar o ambiente bilíngue;

- A aula bilíngue que tem o alemão como língua-alvo [bilingualer Sachfachunterricht mit Deutsch als Zielsprache], muito popular na Europa, em que é ensinado conteúdo em alemão. Algumas vezes, a aula chega a ser monolíngue - caso de parte das disciplinas dos cursos de graduação em Letras/Alemão, enquanto outras são simplesmente ministradas em português; em outras, apenas algumas fases dela o são, ou então a LE é usada na forma de projetos. Essa proposta lembra a imersão estruturada, conforme descrita por Mello (2010: 119-120);

- Os programas de imersão parcial ou total [deutschsprachige (Teil-) Immersionsprogramme], que adquiriram caráter de modelo quanto ao currículo e à elaboração de material na última década e podem prover importantes impulsos para o desenvolvimento da abordagem;

- A aula de conteúdo em alemão sensível à língua [sprachsensibler deutschsprachiger Fachunterricht], que representa uma forma de CLIL mais focada no conteúdo disciplinar, sendo a mais bem documentada das variantes do CLIL e muito presente em escolas alemãs no exterior.

O conceito de language awareness, comumente traduzido para o português como “conscientização linguística", refere-se ao conhecimento explícito sobre a língua e à percepção consciente do uso, do ensino e da aprendizagem dela (cf. GNUTZMANN 2010: 115), além de estar diretamente relacionado à reflexão sobre a língua enquanto procedimento indissociável do uso da mesma (GNUTZMANN 2010: 116). Essa conscientização deve ser o ponto de partida do ensino bilíngue; em outras palavras, a educação bilíngue só pode ser bem-sucedida se o ensino de língua, de modo geral, for reestruturado e orientado por normas plurilíngues, conforme sinaliza Jessner (2008: 15). A abordagem CLIL parece ser uma resposta válida a esses novos questionamentos.

Formatos adequados de aula e de atividades didáticas são fundamentais para que se chegue a determinados graus de competência, bem como para que os alunos já bilíngues ou plurilíngues ampliem e aprofundem seus conhecimentos no conteúdo, sem que os aprendizes da LE fiquem desmotivados pelo grau de complexidade da união entre 
GRILLI, M. - CLIL em alemão no Brasil

conteúdo e língua. Afinal, para que os objetivos definidos para o conteúdo disciplinar possam ser alcançados, deve-se assegurar uma base linguística e comunicativa, a qual, por sua vez, deve ser construída e desenvolvida em conjunto com esse conteúdo disciplinar (VOLLMER 2013: 124).

\section{A competência de leitura}

O Quadro Comum Europeu lista quatro possíveis objetivos da atividade de leitura: ler para orientação geral, para obter informações, para seguir instruções e por prazer (CONSELHO DA EUROPA 2001: 106).

Com a abordagem comunicativa no ensino de LE, os aspectos interculturais que atravessam a prática de leitura ganharam importância. Por esse motivo, o uso de textos autênticos passou a ser cada vez mais estimulado. A definição de autenticidade na qual baseamos este trabalho abrange qualquer texto criado para um contexto de comunicação externo ao ensino de LE, mas que é empregado no ensino, podendo ser totalmente isento de alterações ou sofrer pequenas modificações estruturais, como segmentações. Trata-se, respectivamente, do texto autêntico e do texto autêntico adaptado, conforme tipologia proposta por Andrade e Silva (2017: 24).

Segundo Lutjeharms (2016: 97), o processo de compreensão de leitura é complexo e envolve muitas habilidades. Um livro organizado pelo Departamento de Educação dos Estados Unidos (PREL 2005: 5) afirma ainda que definir a compreensão de leitura como "construir significado a partir do texto" não faz jus à complexidade do fenômeno da compreensão e dos muitos fatores que ela abarca, como as habilidades do leitor, o gênero e as características específicas de cada texto, o tema tratado e o nível de profundidade que se confere a ele, bem como os fatores sociais e culturais que permeiam o momento da leitura.

Diversos pesquisadores já subdividiram o processo de compreensão de leitura em modelos, tipos e níveis. Faremos a seguir uma breve revisão de alguns deles.

O PREL (2005: 7) distingue dois níveis no processo de leitura, ambos fundamentais para uma compreensão eficaz do texto: as habilidades básicas [foundational skills], nível em que se reconhece e decodifica palavras e se obtém a fluência, e os processos de leitura de ordem elevada [higher order reading processes], que abrange os 
GRILLI, M. - CLIL em alemão no Brasil

procedimentos que entram em ação quando o leitor estabelece conexões entre palavras e entre seus conhecimentos prévios e informações presentes no texto.

Falando especificamente da leitura em LE, Würffel (2006: 67) defende o estímulo concomitante das habilidades básicas [Grundfertigkeiten] e dos processos de leitura de ordem elevada [höherstufigen Verstehensprozesse] desde o início da aprendizagem de uma LE. Lutjeharms (2010) cita quatro níveis que compõem o processo de leitura em LE: o nível grafofônico, o nível do reconhecimento de palavras, o processamento sintático e o processamento semântico.

Portanto, parece haver um consenso de que o processo da leitura se constrói em camadas. O processamento do leitor experiente, segundo Lutjeharms (2010: 977), segue a ordem de complexidade descrita pelos autores acima, indo do nível mais baixo ao mais alto - sentido conhecido como bottom-up.

Quanto à compreensão do conteúdo lido, Lutjeharms (2010) cita dois tipos de processamento: o automático, que é rápido e envolve diversos processos em paralelo certamente aqueles supracitados, a saber, decodificação de palavras e de estruturas sintáticas, processamento sintático e semântico, estabelecimento de conexões entre todas essas informações e seus conhecimentos prévios -, e o consciente, necessário para processar informações inesperadas ou ilógicas para o leitor quando suas limitações dificultam a tarefa de apreender o conteúdo.

Já que a compreensão da leitura é construída "de baixo para cima" [from the bottom up], é possível deduzir que as dificuldades de reconhecimento de palavras e processamento sintático dos leitores menos proficientes constituem obstáculos para o entendimento nos níveis mais altos. De acordo com Lutjeharms (2010: 979-980), o reconhecimento de palavras e a análise sintática exigem atenção quando há falhas de processamento nos níveis mais baixos, tornando consciente o processo de compreensão de leitura. Essa falha na decodificação ou falta de conhecimento sobre o conteúdo acaba deixando de lado o nível mais alto do processamento do texto, relativo à semântica, o que pode levar a um entendimento totalmente equivocado da mensagem do texto.

Würffel (2013: 133) também afirma que um baixo conhecimento da língua faz com que aumente o número de inferências e cria obstáculos ao processo de leitura e compreensão, pois recursos que deveriam ter sido ativados nos níveis inferiores ainda não estão plenamente disponíveis nos processos mais altos. 
GRILLI, M. - CLIL em alemão no Brasil

Como minimizar, então, os bloqueios na compreensão de leitura do aprendiz de uma nova língua?

\section{Metodologia}

\subsection{1 ambiente e os participantes}

Este estudo se baseia na seguinte hipótese: cursar uma disciplina CLIL durante a graduação em Letras pode ser de grande auxílio no desenvolvimento da competência de leitura, não só devido ao contato com textos autênticos complexos e voltados para a área acadêmica, mas também porque o input linguístico de uma disciplina CLIL é mais complexo do que aquele que os alunos estão acostumados a receber nas aulas de língua.

No curso de graduação em Letras/Alemão da USP, que serviu de palco para a coleta de dados empíricos, a disciplina que mais está de acordo com os moldes do CLIL chama-se Aquisição/Aprendizagem do Alemão como Língua Estrangeira. Nessa disciplina, de caráter optativo, são apresentados conceitos teóricos da didática de línguas estrangeiras em conjunto com um panorama histórico da área. As explicações são dadas em alemão, traçando-se paralelos com termos-chave em português, e os comentários dos alunos são feitos na língua em que se sentem mais confortáveis. Desse modo, procura-se garantir o desenvolvimento na LE e a aprendizagem satisfatória do conteúdo, dois pilares básicos da abordagem CLIL.

Existem outras disciplinas do curso em que o trabalho com o conteúdo ocorre em paralelo à tematização dos termos linguísticos necessários, como as disciplinas obrigatórias de Literatura Alemã. Entretanto, devido à dificuldade mencionada anteriormente de atingir um nível suficiente de compreensão do alemão ao ingressar no curso sem conhecimentos prévios da língua, as disciplinas de literatura e cultura alemãs costumam sofrer mais adaptações ao português do que a abordagem CLIL tipicamente propõe. Nas palavras de Rösler (2010: 11), “alunos menos avançados leem e discutem literatura traduzida (com a anuência dos docentes)", e cursos avançados são ensinados na língua em que os participantes são mais proficientes. O autor define essa situação da seguinte forma: o currículo é dividido entre aulas de língua, com um ‘conteúdo’ próprio, mas que deveriam interagir com os cursos de conteúdo, e os cursos de conteúdo, que 
GRILLI, M. - CLIL em alemão no Brasil

deveriam ser percebidos como parte da aprendizagem de língua também (RöSLER 2010: 12).

Para a coleta de dados, foram selecionados os alunos do quinto semestre de aulas obrigatórias de Língua Alemã, dentre os quais alguns cursavam a disciplina CLIL Aquisição/Aprendizagem do Alemão como Língua Estrangeira. De um total de 28 alunos matriculados em Língua Alemã V, era importante que nenhum dos participantes da pesquisa tivesse realizado cursos de alemão fora da universidade ou cursado qualquer uma das disciplinas obrigatórias de conteúdo em alemão, pois essas experiências prévias de aprendizagem da língua influenciariam o desenvolvimento de sua competência de leitura.

Assim, foram cumpridos os seguintes requisitos, estabelecidos por Crinon \& Legros (2002), aos quais um estudo experimental em Ciências Humanas deve obedecer: existência de um grupo de controle e um grupo experimental; definição do nível inicial dos membros dos grupos em relação ao aspecto a ser observado (compreensão de leitura em alemão); definição da duração dos procedimentos de observação; realização de uma análise do efeito da aprendizagem em relação à situação inicial mapeada, isto é, um pósteste.

O semestre ideal para matricular-se em Aquisição/Aprendizagem, segundo a grade curricular do curso de Letras/Alemão da USP, é justamente aquele em que os alunos estejam cursando Língua Alemã V, última disciplina obrigatória de ensino de língua na grade curricular do curso e ao final da qual se espera que os alunos tenham atingido nível mínimo B1 de domínio da língua alemã.

A partir daí, foram definidos os seguintes passos metodológicos:

- Avaliar a competência de leitura dos alunos do quinto semestre de Língua Alemã no início, na metade e no fim do semestre letivo;

- Comparar os alunos que cursam Língua Alemã V e a disciplina CLIL com os alunos que cursam somente Língua Alemã V;

- Verificar possíveis diferenças no desenvolvimento da competência de leitura dos alunos desses dois grupos ao longo do semestre letivo;

- Buscar razões para níveis diferentes de desenvolvimento da competência de leitura dos alunos em questão. 
GRILLI, M. - CLIL em alemão no Brasil

\subsection{Os instrumentos de coleta de dados}

O primeiro instrumento empregado foi um questionário de sondagem do perfil dos alunos, preenchido durante uma conversa em tom informal entre a pesquisadora e a turma de Língua Alemã $\mathrm{V}$, de modo a estimular os alunos a refletir sobre suas experiências na graduação e a compartilhá-las. O questionário continha perguntas relativas a três áreas: o percurso dos alunos na graduação em Letras/Alemão; nível de conhecimento do alemão e dificuldades que estavam encontrando durante a aprendizagem da língua; hábitos de leitura em alemão e procedimentos que seguiam em caso de dificuldade na leitura.

Os participantes também realizaram três testes de leitura: um no início do semestre, outro na metade e o último logo antes da avaliação final do curso de Língua Alemã V. Cada um desses testes trabalhou com dois textos autênticos de gêneros diferentes: um texto acadêmico e um texto sobre um tópico da história da literatura alemã. Os textos acadêmicos consistiam em trechos curtos relacionados ao conteúdo visto em aula na disciplina Aquisição/Aprendizagem; os textos relativos à literatura foram retirados de um livro de história da literatura alemã cujo público-alvo são adolescentes [Sachbuch für jugendliche Leser].

$\mathrm{Na}$ aula seguinte à aplicação do questionário, foi aplicado o primeiro teste de leitura. Os participantes tinham, idealmente, vinte minutos para terminar a atividade, e poucos deles precisaram de alguns minutos a mais.

A organização dos tipos de questões nos três testes foi feita da seguinte forma: a primeira questão relativa ao texto acadêmico exigia a mobilização de conhecimentos prévios em conjunto com pistas dadas pelo texto, e a segunda exigia pesquisa ao longo do texto. Essas questões eram de múltipla escolha e continham apenas uma alternativa correta. A terceira e última questão e as três questões relativas ao texto sobre literatura eram todas dissertativas, variando entre perguntas cuja resposta podia ser diretamente encontrada em uma frase e perguntas que exigiam certa pesquisa ao longo do texto. Dessa forma, foram evitadas as questões que fizessem referência a conhecimentos prévios dos alunos.

Para a correção, foi utilizado como base o gabarito preparado, mas respostas dissertativas que divergissem ligeiramente dele também puderam ser aceitas como corretas. Para ser considerada certa, a resposta não poderia ser uma tentativa de contornar a pergunta, tanto por mera reformulação como por inserção de informações que não constassem do texto. Tampouco poderia tratar-se de uma mera cópia do trecho 
GRILLI, M. - CLIL em alemão no Brasil

correspondente em alemão, já que os enunciados continham a instrução explícita, reforçada oralmente no momento da aplicação, de que o aluno deveria responder todas as questões em português. A resposta que introduzisse termos em alemão na estrutura da frase em português, fugisse levemente do que foi perguntado devido a uma possível falta de vocabulário ou que fornecesse apenas parte das informações solicitadas seria considerada parcialmente correta. $\mathrm{O}$ mesmo valeria para frases retiradas diretamente do texto, que contivessem termos pontuais traduzidos do alemão; entretanto, esses termos não poderiam modificar completamente o sentido da frase, pois tornariam a resposta incorreta.

Dentre os 28 alunos matriculados em Língua Alemã V, somente três deles preencheram todos os requisitos - isto é, haviam ingressado no curso de Letras sem conhecimentos prévios de língua alemã, responderam ao questionário inicial e participaram de todas as três atividades de leitura. Um deles cursava apenas Língua, e dois cursavam simultaneamente Língua e Aquisição.

Após uma análise preliminar de seu desempenho nos testes, esses três participantes selecionados aceitaram participar de uma entrevista semidirigida, em que foram colhidas mais informações sobre os seguintes tópicos: por que decidiram estudar Germanística; quais outras línguas estrangeiras já aprenderam; como tem sido o processo de aprendizagem do alemão; com que frequência têm contato com o alemão e outras línguas estrangeiras; se já estiveram em alguma região onde se fala outra língua; se já trabalham na área de Letras; para os que cursaram Aquisição, quais foram suas impressões sobre a disciplina.

\section{Análise}

\subsection{Perfis}

Dos seis alunos que responderam ao questionário e realizaram os três testes de leitura, três não tinham tido qualquer experiência de aprendizagem de alemão ao ingressar na graduação. Um cursava apenas Língua Alemã V, e os outros dois cursavam concomitantemente Língua Alemã V e Aquisição/Aprendizagem do Alemão como Língua Estrangeira. Vamos traçar o perfil desses três alunos. 
GRILLI, M. - CLIL em alemão no Brasil

Dentre os três alunos selecionados, aquele que cursava apenas Língua Alemã $\mathrm{V}$ será chamado S1; os outros dois, que cursavam também Aquisição/Aprendizagem, serão chamados S2 e S3.

a) S1: Declarou que seu nível de conhecimento geral e de leitura na língua alemã é A2. Afirmou ter tido uma "experiência traumática" com as aulas de Língua Alemã I e, no ano seguinte, trancou o curso durante um ano. Em sua opinião, a progressão do material didático é rápida demais, e suas maiores dificuldades são a sobrecarga de conteúdo e a insegurança ao falar. Quando encontra dificuldades na leitura, procura traduzir os textos. Na primeira atividade de leitura, acertou quase metade das questões propostas; na segunda, errou quase todas; na terceira, acertou pouco mais da metade.

b) S2: Este aluno, que declara estar no nível B1 em conhecimentos gerais da língua alemã e também na competência de leitura, afirma que o curso tem cumprido suas expectativas. Realiza pesquisa de iniciação científica na área de didática do alemão, e por isso decidiu cursar Aquisição/Aprendizagem. Afirma encontrar dificuldades tanto no vocabulário quanto na gramática, e procura consultar dicionários em português e inglês. Na primeira atividade de leitura, acertou quase todas as questões; na segunda, todas; na terceira, quase todas novamente.

c) S3: Este último participante selecionado afirma situar-se entre os níveis A2 e B1, tanto em conhecimentos gerais da língua alemã quanto em relação à leitura. Considera as aulas de língua "muito expositivas e pouco dinâmicas". Ao deparar-se com dificuldades na leitura, revisa suas anotações de gramática. Decidiu cursar Aquisição/Aprendizagem por interessar-se por didática, mas já havia se matriculado na disciplina anteriormente, tendo trancado a matrícula por sentir-se inseguro e pressionado. Na primeira atividade de leitura, errou quase todas as questões; na segunda, acertou cerca de metade; na terceira, acertou quase todas.

Portanto, somente um dos alunos selecionados apresentou melhora efetiva na compreensão de leitura ao longo do semestre, e trata-se de um aluno da disciplina CLIL. O estudo adquire, a partir de então, um viés comparativo: o que teria levado somente um dos participantes a essa melhora?

Vamos categorizar esses alunos de acordo com as informações obtidas por meio do questionário e das entrevistas. 
GRILLI, M. - CLIL em alemão no Brasil

\subsection{Os níveis de conhecimento}

Em primeiro lugar, vamos observar se os níveis de conhecimento do alemão que os participantes declararam são condizentes com o que foi demonstrado nos testes de leitura.

Relacionando os índices de acertos das questões propostas nas atividades e os níveis declarados, temos o seguinte:

\begin{tabular}{|c|c|c|}
\hline \multicolumn{3}{|c|}{$\begin{array}{c}\text { Nível e índice de acertos } \\
\text { dos participantes }\end{array}$} \\
\hline Aluno & Nível & $\mathbf{N}^{\mathbf{0}}$ de acertos \\
\hline S1 & A2 & baixo \\
S2 & B1 & alto \\
S3 & A2/B1 & médio \\
\hline
\end{tabular}

Quadro 1. Nível de conhecimento declarado e índice de acertos nas atividades

Em uma primeira análise, percebe-se que os participantes demonstram ter consciência de sua competência, mantendo-se entre nível A2 em leitura com baixo índice de acertos nas atividades, e nível B1 com maior índice de acertos. S3 selecionou ambos os níveis ao responder ao questionário, e teve um índice médio de acertos.

Entretanto, S3 foi o único participante que apresentou melhora significativa entre a primeira e a terceira atividade. Vamos investigar os motivos para isso.

\subsection{Por que alemão?}

Os três alunos entrevistados afirmaram ter entrado na Habilitação e, por vezes, mesmo na graduação em Letras, para aprender uma língua. Portanto, o objetivo de aprender alemão foi considerado, por alguns, como um fim em si mesmo, sem que houvesse um plano claro a respeito do que fazer com a língua. Para outros, a aprendizagem da língua era um meio para atingir um fim, como o de aprofundar o contato com falantes nativos ou os conhecimentos acerca da cultura dos países de língua alemã.

A disciplina de Aquisição/Aprendizagem não é obrigatória nem mesmo para os alunos que decidiram cursar a modalidade Licenciatura. No questionário, todos os alunos da disciplina afirmaram que pretendem lecionar alemão em colégios e em cursos de idiomas. Por isso, é possível afirmar que nenhum deles estava desmotivado em relação à aprendizagem do alemão. Nas entrevistas, S2 e S3 afirmaram ter contato quase diário com o alemão, através de leituras variadas, aplicativos para celular e músicas. 
GRILLI, M. - CLIL em alemão no Brasil

Já S1, que não cursava Aquisição/Aprendizagem ou qualquer outra disciplina optativa do alemão e que teve o mais baixo desempenho nas três atividades dentre todos os participantes, é o único que parece desmotivado: ele passou por experiências negativas com a aprendizagem do alemão logo no início da habilitação, o que o levou a afastar-se da língua durante um ano, relatando sentir-se sobrecarregado pelo curso. Não tem o costume de ler textos em alemão sem que isso lhe tenha sido exigido pelos professores, e procura traduzi-los quando tem dificuldades de compreensão.

$\mathrm{Na}$ entrevista, S1 afirmou que esperava que o alemão "caísse do céu" como o inglês, língua que aprendeu sem grande esforço, pois “as coisas fluíam”, mas logo percebeu que essa estratégia não funcionaria com o alemão. Ou seja, S1 não foi o único participante da pesquisa que não apresentou melhoria na leitura ao longo do semestre, mas o único dentre os selecionados que não desenvolveu um perfil autônomo; na entrevista, assumiu não ter feito sua parte. Assim, o próprio perfil do aluno já parece indicar por que ele não decidiu cursar a disciplina CLIL e explica, em parte, o baixo desenvolvimento de sua compreensão de leitura.

Desse modo, é compreensível que S1 não tenha progredido na competência de leitura ao longo do semestre. Vamos aprofundar a comparação entre os alunos.

\subsection{Outras línguas estrangeiras}

Somente S2 mencionou, no questionário, utilizar seus conhecimentos de inglês como recurso para a compreensão de leitura em alemão. Esse fato suscita a questão da experiência prévia dos alunos em aprendizagem de línguas.

$\mathrm{S} 2$ estudou inglês durante quatro anos e meio numa conhecida escola de idiomas e complementou seu conhecimento com um curso online. S1 também estudou inglês durante muitos anos e hoje leciona a língua.

S3 estudou inglês desde a infância e também fala espanhol. Dentre os trabalhos que já realizou na área de Letras, trabalhou com tradução inglês-português e deu até aulas de reforço de alemão para um aluno de colégio alemão. Atualmente, faz serviços de transcrição de áudio para trabalhos acadêmicos.

Desse modo, o único aluno que já tinha conhecimento de mais de uma LE antes de iniciar o estudo do alemão foi aquele cuja competência de leitura melhorou significativamente ao longo do semestre. Entretanto, o conhecimento de outras línguas antes do início da aprendizagem do alemão não tornou menos heterogêneos os perfis dos 
GRILLI, M. - CLIL em alemão no Brasil

três participantes selecionados. Em outras palavras, o conhecimento de outras LEs não pareceu desempenhar, aqui, um papel conclusivo em meio à complexidade de fatores envolvidos no desenvolvimento da competência de leitura em alemão.

Vamos verificar a seguir os tipos de erros cometidos pelos alunos nos testes de leitura.

\subsection{Tipos de erros}

Observando as respostas de cada um dos três participantes, foram encontrados seis tipos de erros, listados a seguir em escala crescente de gravidade.

\begin{tabular}{|c|l|}
\hline \multicolumn{2}{|c|}{ Definição dos erros cometidos pelos participantes } \\
\hline Tipo de erro & \begin{tabular}{l}
\multicolumn{1}{c|}{ Descrição } \\
o aluno traduziu incorretamente para o português, ou deixou em \\
alemão, apenas termos pontuais do texto original
\end{tabular} \\
\hline 1 & $\begin{array}{l}\text { o aluno alterou o significado de termos ou a relação entre orações de } \\
\text { um período do texto original ao traduzi-lo }\end{array}$ \\
\hline 3 & $\begin{array}{l}\text { o aluno selecionou corretamente o trecho que continha a resposta, mas } \\
\text { o copiou em alemão }\end{array}$ \\
\hline 4 & $\begin{array}{l}\text { o aluno deixou a resposta incompleta, isto é, traduziu ou mesmo } \\
\text { copiou em alemão apenas uma parte do trecho correto }\end{array}$ \\
\hline 5 & $\begin{array}{l}\text { o aluno respondeu à questão sem basear-se no texto, mas somente em } \\
\text { conhecimentos prévios }\end{array}$ \\
\hline 6 & o aluno não respondeu à questão \\
\hline
\end{tabular}

Quadro 2. Definição dos tipos de erro cometidos pelos participantes nos testes de leitura (elaborado pela autora)

No tipo de erro 1, o aluno selecionou corretamente o trecho que continha a resposta à questão e chegou a vertê-lo para o português, mas cometeu erros pontuais, que não alteram as relações estabelecidas no período.

No erro 2, os equívocos cometidos ao transcrever a passagem em português chegam a alterar o sentido do trecho, estabelecendo relações temporais ou causais falsas - isto é, ao contrário do que ocorre com o erro 1, houve obstáculos na significação da mensagem.

O erro 3 consiste apenas na não-observância da instrução - grafada em negrito antes de cada bloco de questões dissertativas relativas a cada texto - de escrever as respostas em português. Ao selecionar corretamente o trecho que continha a resposta da pergunta, o aluno prova tê-lo compreendido, bem como a relação entre a questão e o trecho. É possível que não tenha prestado atenção à instrução de responder em português, ou mesmo que não tenha encontrado palavras muito adequadas para expressar a mesma 
GRILLI, M. - CLIL em alemão no Brasil

ideia na L1; pode ser ainda que tenha preferido não permitir que essa tarefa lhe tomasse muito do tempo reservado para a execução do teste. Entretanto, esse erro é considerado mais grave do que o erro 2, porque o aluno que procura as palavras em português arriscase mais do que aquele que deixa o trecho em alemão.

O erro 4 são as respostas incompletas, que poderiam ser causadas pela falta de entendimento de algum ponto do texto ou por mera falta de atenção ao responder às questões, mas que também denotam que a apropriação do conteúdo foi prejudicada. $\mathrm{O}$ erro 5 foi observado em respostas que não estavam incorretas, mas que continham informações não fornecidas pelo texto. Por fim, o erro 6 foi a ausência de resposta a alguma questão.

Assim, é possível classificar os erros 1 e 2 como de menor gravidade, os erros 3 e 4 como medianos, e os erros 5 e 6 como mais graves, de acordo com a dificuldade que o aluno demonstra para compreender o trecho e com a discrepância entre o que ele parece ter compreendido e a mensagem original.

Os tipos de erros cometidos pelos alunos nas questões dissertativas dos testes estão representados nas tabelas abaixo, sob o número da questão e ao lado do número do teste. Os espaços em branco correspondem a questões que foram respondidas corretamente. Em caso de um erro poder enquadrar-se em duas categorias, foi indicado o de número mais elevado, isto é, o mais grave.

\begin{tabular}{|l|c|c|c|c|c|}
\hline \multicolumn{6}{|c|}{ Erros: S1 } \\
\hline & Texto 1 & \multicolumn{3}{|c|}{ Texto 2 } \\
\hline & $3 \mathrm{a}$ & $3 \mathrm{~b}$ & 1 & 2 & 3 \\
\hline Teste 1 & $\mathbf{5}$ & 6 & & 4 & 6 \\
\hline Teste 2 & 5 & 5 & 5 & 4 & 6 \\
\hline Teste 3 & 6 & 6 & 2 & & \\
\hline
\end{tabular}

Tabela 2. Erros do aluno S1

\begin{tabular}{|l|l|l|l|l|l|}
\hline \multicolumn{5}{|c|}{ Erros: S2 } \\
\hline & Texto 1 & \multicolumn{3}{|c|}{ Texto 2 } \\
\hline & $3 \mathrm{a}$ & $3 \mathrm{~b}$ & 1 & 2 & 3 \\
\hline Teste 1 & & & & 3 & 4 \\
\hline Teste 2 & & & & & \\
\hline Teste 3 & & & $\mathbf{3}$ & & \\
\hline
\end{tabular}

Tabela 3. Erros do aluno S2

\begin{tabular}{|l|c|c|c|c|c|}
\hline \multicolumn{6}{|c|}{ Erros: S3 } \\
\hline & Texto 1 & \multicolumn{3}{|c|}{ Texto 2 } \\
\hline & $3 \mathrm{a}$ & $3 \mathrm{~b}$ & 1 & 2 & 3 \\
\hline Teste 1 & 3 & 6 & 3 & 3 & 4 \\
Teste 2 & & & 6 & $\mathbf{4}$ & \\
\hline Teste 3 & & 3 & 1 & 1 & 1 \\
\hline
\end{tabular}

Tabela 4. Erros do aluno S3

Inicialmente, percebe-se que S1 cometeu mais erros nos testes do que seus colegas, e também os de maior gravidade: além de ter deixado muitas questões em branco, a maior parte de suas respostas não se baseou no conteúdo do texto. Aquelas que faziam referência ao texto tiveram seu sentido alterado ou estavam incompletas. Somente três de suas respostas estavam corretas.

As respostas incorretas de S2, embora muito escassas, continham erros de gravidade média, pois chegaram a alterar o teor da mensagem transmitida pelo texto. 
GRILLI, M. - CLIL em alemão no Brasil

Já no caso de S3, o que permite afirmar que houve progresso em sua compreensão de leitura é a combinação de dois fatores: a diminuição da quantidade de erros cometidos e a transição para mais erros leves ou acertos do que erros graves.

A seguir retoma-se a teoria, visando estabelecer relações entre os perfis e históricos dos alunos, os tipos de erros que cometeram e o progresso na leitura em alemão - ou a ausência dele.

7.6 Os erros à luz do referencial teórico

Retomando os pressupostos teóricos deste trabalho, podemos propor a seguinte classificação dos tipos de erros descritos na seção 7.5:

\begin{tabular}{|c|c|c|c|}
\hline \multicolumn{4}{|c|}{ Tipos de erros cometidos nos testes de leitura } \\
\hline Erro & $\begin{array}{c}\text { Descrição } \\
\text { o aluno traduziu incorretamente para o } \\
\text { português, ou deixou em alemão, apenas } \\
\text { termos pontuais do texto original }\end{array}$ & elevadas & $\begin{array}{c}\text { Nível } \\
\text { processamento } \\
\text { semântico }\end{array}$ \\
\hline 2 & $\begin{array}{c}\text { o aluno alterou o significado de termos ou a } \\
\text { relação entre orações de um período do texto } \\
\text { original ao traduzi-lo }\end{array}$ & elevadas & $\begin{array}{c}\text { processamento } \\
\text { semântico/ } \\
\text { processamento } \\
\text { sintático }\end{array}$ \\
\hline 3 & $\begin{array}{c}\text { que continha a resposta, mas o copiou em } \\
\text { alemão }\end{array}$ & elevadas & $\begin{array}{c}\text { processamento } \\
\text { semântico/ } \\
\text { processamento } \\
\text { sintático }\end{array}$ \\
\hline 4 & $\begin{array}{c}\text { o aluno deixou a resposta incompleta, isto é, } \\
\text { traduziu ou mesmo copiou em alemão } \\
\text { apenas uma parte do trecho correto }\end{array}$ & básicas & $\begin{array}{c}\text { processamento } \\
\text { sintático/ } \\
\text { reconhecimento } \\
\text { de palavras }\end{array}$ \\
\hline 5 & $\begin{array}{c}\text { o aluno respondeu à questão sem basear-se } \\
\text { no texto, mas somente em conhecimentos } \\
\text { prévios }\end{array}$ & básicas & $\begin{array}{c}\text { reconhecimento } \\
\text { de palavras }\end{array}$ \\
\hline 6 & o aluno não respondeu à questão & básicas & $\begin{array}{c}\text { reconhecimento } \\
\text { de palavras }\end{array}$ \\
\hline
\end{tabular}

Quadro 3. Relação entre os erros cometidos nos testes e as habilidades e níveis do processamento de leitura, com base no PREL (2005) e em Lutjeharms (2010)

A completa ausência de resposta a uma questão ou a resposta não embasada no texto indicariam que o leitor não encontrou, no texto, as palavras relacionadas ao tema. Já a resposta incompleta poderia advir do não reconhecimento de algumas das palavras 
GRILLI, M. - CLIL em alemão no Brasil

pertinentes ou da estrutura frástica que denotasse a continuidade do mesmo assunto, isto é, de uma falha no processamento sintático.

A reprodução de um trecho integralmente em alemão pode ser interpretada como falha no processamento semântico ou sintático, a depender do caminho percorrido pelo leitor ao inferir significados. Embora a apreensão de significado consista numa questão de semântica, não é possível afirmar que o leitor não se arriscou a transpor o trecho para o português pela falta de conhecimento do vocabulário; o não entendimento da informação contida em um período do texto pode ter sido causado pela não apreensão das relações entre as frases ou ideias apresentadas.

O mesmo pode ser dito sobre a compreensão equivocada do teor da frase: o leitor de nível B1/B2 que se depara com obstáculos para compreensão de um complexo texto autêntico frequentemente não entende a maneira como o conteúdo está estruturado. A semântica participa na medida em que o significado surge por meio da estrutura estabelecida pela sintaxe, além de estar relacionada ao conteúdo das próprias unidades lexicais.

Por fim, a resposta que contivesse algumas palavras em alemão, ou todo o trecho correspondente, demonstraria que o aluno reconheceu as palavras e processou a estrutura sintática da frase que continha a resposta, ficando a poucos passos de apreender integralmente o conteúdo do trecho, só lhe faltando decodificar o conteúdo de algumas das unidades lexicais.

Portanto, a classificação dos erros cometidos pelos participantes de acordo com as habilidades de leitura e os níveis de processamento não segue categorias estanques, baseadas em justificativas limitadas. Como não havia alunos iniciantes entre os participantes e, em decorrência disso, nenhuma das tarefas propostas nos testes exigia apenas um conhecimento elementar, não foram percebidos erros no nível grafofônico.

Sabemos que falhas de processamento nos níveis mais baixos fazem com que o leitor volte sua atenção para o reconhecimento de palavras e a análise sintática (LUTJEHARMS 2010: 979-980). Esse parece ter sido o caso de S1, cujos erros demonstram que ele não compreendeu a maior parte do conteúdo dos textos, deixando de responder às questões ou fazendo uso de outros conhecimentos para comentar os temas propostos. Portanto, seu processamento textual ainda não é automático, mas consciente, conforme Lutjeharms (2010) define o caminho percorrido pelo leitor quando suas limitações dificultam a assimilação do conteúdo. 
GRILLI, M. - CLIL em alemão no Brasil

Além disso, Lutjeharms (2010 979-980) afirma que essas falhas de processamento podem surgir no momento da decodificação ou ser oriundas da falta de conhecimento sobre o conteúdo do texto lido; a falta de conhecimento certamente não é o problema de $\mathrm{S} 1$, pois ele demonstrou desenvoltura ao responder pelo menos três questões sem o apoio do texto. Se o problema não fosse a decodificação das palavras, o aluno teria esboçado respostas minimamente baseadas na ideia principal do texto.

Outro argumento nesse sentido é o de que os leitores que mais fazem inferências são aqueles com menor nível de proficiência em leitura (KATO 1990: 65). S1 fez muitas inferências a respeito do conteúdo trabalhado nos textos, as quais levaram suas respostas a distanciar-se desse conteúdo. Em resumo, percebe-se que o aluno ainda não consolidou conhecimentos básicos de língua alemã; na entrevista, afirmou ter total consciência disso.

Assim, falhas no reconhecimento de palavras e no processamento sintático acabam por relegar a segundo plano o nível mais alto do processamento da leitura, relativo à semântica. Isso pode conduzir a um entendimento equivocado da mensagem do texto, inclusive por leitores com menor necessidade de fazer inferências. Foi o caso de S2: por duas vezes, o aluno compreendeu de forma equivocada o significado de um período composto, devido a inferências incorretas sobre um verbo. Porém, nenhum de seus erros se deu no nível do reconhecimento de palavras, indicando que S2 tem bases sólidas sobre as quais se apoiar; seu alto índice de acertos prova que ele já consegue lidar com textos mais complexos, além de estar familiarizado com textos da área de didática do alemão.

No caso de S3, a análise sintática transcorreu automaticamente. À exceção das duas únicas perguntas às quais não respondeu, foi capaz de encontrar os trechos correspondentes às questões propostas, mesmo que, algumas vezes, de forma incompleta. Seu processamento intuitivo das informações contidas nos textos se enquadra perfeitamente no que Lutjeharms (2010) chama de processamento automático: a decodificação de palavras e de estruturas sintáticas, o processamento semântico e o estabelecimento de conexões entre todos esses níveis de informação ocorrem em alta velocidade. A aparente dificuldade do aluno em transpor os trechos para o português pode ser interpretada como mais uma prova de que dominou os níveis básicos do processamento textual em alemão, pois não havia mais a necessidade de pensar em português ao tentar compreender textos autênticos - comprovando que o processamento da leitura acontece de baixo para cima. Ao longo do semestre, essa dificuldade deu lugar 
GRILLI, M. - CLIL em alemão no Brasil

à capacidade de apropriar-se tão bem do conteúdo lido a ponto de encontrar, em sua L1, outras palavras para expressar os mesmos conceitos.

Está claro que o desafio é diferenciar quais desses dados são responsáveis pela melhora na competência de leitura de S3, ao passo que S2, aluno cujo perfil é bastante parecido, manteve um desempenho constante ao longo do semestre, mesmo tendo obtido um índice de acertos maior que S3 desde o primeiro teste. Ambos cursaram Aquisição/Aprendizagem, têm interesse na área de didática de ALE e pretendem tornarse professores. Voltaremos a essa reflexão no capítulo a seguir.

\section{Discussão dos resultados}

Comparando S2 e S3, destacam-se em ambos o perfil autônomo e a sedimentação da habilidade básica de reconhecimento de palavras. Porém, enquanto S2 afirmou no questionário ter se matriculado em Aquisição/Aprendizagem porque a disciplina dialoga com o tema de sua iniciação científica, o interesse de S3 em fazer iniciação científica surgiu já durante o curso da disciplina. A partir daí, sua competência de leitura evoluiu, pois o crescimento de seu interesse fez com que ele tivesse que se esforçar para ler textos complexos.

Isso permite inferir que S2 já se encontrava no nível suficiente de leitura exigido para cursar Aquisição/Aprendizagem, pois já tinha iniciado a prática de ler textos técnicos autênticos meses antes. Sua competência de leitura não evoluiu ao longo da disciplina porque já estava além do esperado para um aluno que, de acordo com as disciplinas de Língua Alemã já cursadas, deveria estar completando o nível B1 ao final daquele semestre. Segundo o Quadro Comum Europeu (CONSELHO DA EuROPA 2001: 107), um leitor de nível B1 é "capaz de ler textos objetivos simples acerca de assuntos relacionados com a sua área de interesse, com um grau satisfatório de compreensão". S2 mostrou-se capaz de ler mais do que textos simples, pois quase não cometeu erros ao responder às questões relativas a textos de um gênero com o qual, segundo suas respostas ao questionário, nunca havia tido contato. Por isso, o aluno está mais próximo da definição de leitor de nível B2:

É capaz de ler com um elevado grau de independência, adaptando o estilo e a velocidade de leitura a diferentes textos e fins e utilizando de forma seletiva fontes de referência adequadas. Possui um amplo vocabulário de leitura, mas pode sentir alguma dificuldade com expressões idiomáticas pouco frequentes (CONSELHO DA EUROPA 2001: 107). 
S3, por sua vez, iniciou o semestre sem saber o que esperar da disciplina, e sua motivação cresceu à medida que percebeu que o tema lhe interessava. $\mathrm{O}$ dado que demonstra mais significativamente sua progressão no desenvolvimento da competência de leitura é ter transicionado de respostas copiadas diretamente do texto, em alemão, para tentativas de reescrevê-las em português, geralmente bem-sucedidas. Desse modo, percebe-se que S3 é o típico aluno de Aquisição/Aprendizagem, ao contrário de S2, que já havia adiantado leituras dos gêneros textuais trabalhados na disciplina.

Isso permite afirmar que o aluno que tenha concluído satisfatoriamente os quatro primeiros semestres de aulas de língua é capaz de avançar na compreensão de leitura de textos autênticos ao cursar Aquisição/Aprendizagem.

\section{Considerações finais}

Nesta última seção, serão apresentadas reflexões sobre a análise dos dados, e a hipótese inicial será retomada e discutida.

Para determinar se houve melhora na competência de leitura, foi necessário combinar procedimentos de análise quantitativa e qualitativa. Somente a quantidade de erros cometidos ou a classificação de sua gravidade não forneceriam dados claros sobre o desenvolvimento de cada aluno.

A quantidade de participantes selecionados para análise foi reduzida por dois motivos: o primeiro é pelo fato de muitos deles deixaram de comparecer a alguma das aulas em que os testes foram aplicados, impossibilitando o acompanhamento longitudinal de sua competência de leitura; o segundo é porque, dentre os presentes, vários já tinham estudado alemão antes de escolher essa Habilitação na graduação. Apesar disso, a análise dos dados permitiu observar que o aluno que conclui satisfatoriamente alguns semestres de aulas de língua é capaz de avançar na compreensão de leitura de textos autênticos ao cursar uma disciplina CLIL. A razão para tanto é que, quando as habilidades básicas são satisfatoriamente dominadas pelo leitor, elas oferecem suporte para a antecipação e a organização das novas informações na memória (LUTJEHARMS 2010: 978), finalizando, assim, o percurso bottom-up.

Desse modo, é fundamental estabelecer o domínio das habilidades básicas de processamento da leitura como foco dos quatro primeiros semestres de aulas de língua alemã, bem como garantir a oferta de ao menos uma disciplina CLIL como oportunidade 
GRILLI, M. - CLIL em alemão no Brasil

de transição para as disciplinas de conteúdo majoritariamente monolíngues. Apesar de todas as dificuldades envolvidas no ensino universitário de alemão no Brasil, o desafio de levar a cabo esse domínio satisfatório dos níveis básicos do alemão pode ser recompensador.

Percebe-se ainda que, aparentemente, a intenção de elaborar três testes com o mesmo nível de dificuldade foi bem-sucedida, pois variam os testes em que cada aluno cometeu mais acertos ou mais erros.

Dados os benefícios da abordagem CLIL, tanto sobre a aprendizagem do conteúdo quanto sobre o desenvolvimento de competências na língua, conforme procuramos demonstrar aqui, pode ser interessante pensar na possibilidade de aumentar a oferta de disciplinas CLIL nos cursos de graduação em Letras/Alemão. Diante dos conhecidos obstáculos enfrentados nas universidades públicas brasileiras, como a heterogeneidade dos currículos de norte a sul do país, uma alternativa mais plausível seria oferecer disciplinas CLIL como obrigatórias, ou, ainda, adaptar algumas disciplinas obrigatórias ministradas em alemão para o modelo CLIL, fazendo uso de ferramentas como a adaptação da linguagem utilizada pelo professor durante a aula. Outra alternativa seria implementar algumas aulas nos moldes do CLIL desde as disciplinas iniciais de Língua Alemã, inclusive levando em consideração a atual obrigatoriedade de se trabalhar com temas transversais.

Dessa maneira, este trabalho procurou apresentar uma pequena contribuição para diminuir a lacuna entre a teoria de aplicação do CLIL e seus efeitos práticos sobre a aprendizagem do alemão como língua estrangeira.

\section{Referências bibliográficas}

AndRAde E Silva, M. K. Autenticidade de materiais e ensino de línguas estrangeiras. Pandaemonium Germanicum, v. 20, n. 31, 2017, p. 1-29.

ARAÚJO, F. R. de; UPHOFF, D. Três décadas de pesquisa sobre a formação de professores de alemão no Brasil. In: Anais do $2^{\circ}$ Congresso da Associação Brasileira de Estudos Germanísticos 2017. Florianópolis: CCE/UFSC, 2017, p. 275-282. Disponível em: https://bit.ly/2ImtUuE Acesso: 3 jan. 2019.

AuswäRTIGES AmT. Deutsch als Fremdsprache weltweit. Datenerhebung 2015. Disponível em: https://bit.ly/2H0DPVX. Acesso em: 30 out. 2018.

BLuME, R. F. Prática como componente curricular - desafio e oportunidade na formação universitária de professores de alemão no Brasil. In: BOHUNOVSKY, R. (org.). Ensinar alemão no Brasil: contextos e conteúdos. Curitiba: Editora UFPR, 2011, p. 53-68. 
GRILLI, M. - CLIL em alemão no Brasil

Bolacio Filho, E. S.; Moura, M. Um novo velho método? A tradução na formação de professores de alemão como língua estrangeira. In: MourA, M. et al. (Orgs.). Ensinoaprendizagem de alemão como língua estrangeira: teoria e práxis. Rio de Janeiro: Letra Capital, 2014, p. 75-90.

BRASIL. Lei $n^{\circ}$ 9394, de 20 de dezembro de 1996. Estabelece as diretrizes e bases da educação nacional. Brasília, DF: 1996. Disponível em: https://bit.ly/2fWX88v Acesso em: 26 nov. 2018.

BRITISH COUNCIL. Demandas de aprendizagem no Brasil. Elaborado com exclusividade para o British Council pelo Instituto de Pesquisa Data Popular. São Paulo, 2014. Disponível em: https://bit.ly/2zwZ11X. Acesso em: 18 out. 2018.

CASOTTI, J. B. C.; FInARDI, K. R. Abordagens inclusivas no ensino de línguas: desafios para a formação docente. (Con)textos Linguísticos, Espírito Santo, v. 10, n. 15, 2016, p. 63-76.

CONSELHO DA EUROPA. Quadro europeu comum de referência para línguas: aprendizagem, ensino, avaliação. Porto: Edições ASA, 2001.

CRINON, J.; LEgROS D. Introduction. In: LEgROS, D.; CRINON, J. Psychologie des apprentissages et multimédia. Paris: Armand Colin, 2002, p. 11-16.

Evangelista, M. C. R. G. Die Deutschlehrerausbildung an brasilianischen universitäten: Neue Erkenntnisse? In: Anais do $8^{\circ}$ Congresso Brasileiro de Professores de Alemão, 2011, s/p. Disponível em: https://bit.ly/2PUAmMQ Acesso em: 3 dez. 2018.

FreIRE, P. Pedagogia da autonomia: saberes necessários à prática educativa. São Paulo: Paz e Terra, 1996.

FRITZEN, M. P. "Ich kann mein Name mit letra junta und letra solta schreib": deutschportugiesisches Code-Switching in einer Grundschule im südbrasilianischen Immigrationsgebiet. Pandaemonium Germanicum, São Paulo, v. 11, 2007, p. 25-156.

FRITZEN, M. P.; EWALD, L. "Aqui somos protegidos pelas nossas quatro paredes. Aqui nós falamos alemão": histórias de letramentos interculturais no Vale do Itajaí, SC. Trabalhos em Linguística Aplicada, Campinas, v. 52, n. 2, 2013, p. 239-258.

GnutzMann, C. Language Awareness. In: HAllet, W.; KöNIGS, F. G. (orgs.). Handbuch Fremdsprachendidaktik. Seelze: Kallmeyer-Klett, 2010. p. 115-119.

Guimarães, R. M. Planejamento CLIL por tarefas: integrando temas e língua para fins específicos na educação profissional. Dissertação (mestrado) - Instituto de Letras, Universidade de Brasília, Brasília, 2015.

HAATAJA, K.; Wicke, R. E. Sprache und Fach Integriertes Lernen in der Zielsprache Deutsch (CLILiG). Fremdsprache Deutsch, v. 27, n. 54, 2016, p. 3-9.

JESSNER, U. Teaching third languages: findings, trends and challenges. Language teaching, v. 41, 2008, p. 15-56.

Kato, M. O aprendizado da leitura. 3. Ed. São Paulo: Martins Fontes, 1990 [1985].

KöNIGS, F. G. Mehrsprachigkeit und bilingualer Unterricht/CLIL: die Begriffsvielfalt von Mehrsprachigkeit. In: HALLET, W.; KÖNIGS, F. G. (orgs.). Handbuch Bilingualer Unterricht. Content and language integrated learning. Seelze: Kallmeyer-Klett, 2013. p. 32-39.

Koch, I. V.; EliAS, V. M. Ler e compreender: os sentidos do texto. 2. ed. São Paulo: Contexto, 2006.

LEÃO, R.; FinARDI, K. Ensino de conteúdos diversos por meio da língua e construção de cidadania: o caso do ensino de nutrição por meio do inglês. In: CONEL - Congresso Nacional de Estudos Linguísticos, 2, 2013, Espírito Santo. Anais eletrônicos [...]. Espírito Santo: Universidade Federal do Espírito Santo, 2014. Disponível em: https://bit.ly/2V7kk2U. Acesso em: 28 fev. 2019.

LutJEHARMS, M. Leseverstehen. In: BURWITZ-MELZER, E. et al. Handbuch Fremdsprachenunterricht. 6. ed. Tübingen: A. Francke Verlag, 2016. p. 97-102.

Pandaemonium, São Paulo, v. 22, n. 38, set.-dez. 2019, p. 48-74 
GRILLI, M. - CLIL em alemão no Brasil

LutJeharms, M. Vermittlung der Lesefertigkeit. In: KrUMM, H.-J. Deutsch als Fremd- und Zweitsprache. Ein internationales Handbuch, 1. ed. Berlin: De Gruyter Mouton, 2010. p. 976-982.

MARSH, D. et al. European framework for CLIL teacher education - a framework for the professional development of CLIL teachers. Graz: European Centre for Modern Languages of the Council of Europe, 2005. Disponível em: https://bit.ly/2DSw4jY. Acesso em: 29 out. 2018.

Mello, H. A. B. Educação bilíngue: uma breve discussão. Horizontes de Linguística Aplicada, Brasília, v. 9, n. 1, 2010, p. 118-140.

MourA, Selma de Assis. Com quantas línguas se faz um país? Concepções e práticas de ensino em uma sala de aula na educação bilíngue. Dissertação (Mestrado) - Faculdade de Educação, Universidade de São Paulo, São Paulo, 2009.

OECD - ORGANISATION FOR ECONOMIC CO-OPERATION DEVELOPMENT. Brazil. In: Country Note - Results from PISA 2015. Paris: OECD, 2016. Disponível em: https://bit.ly/2V3Z4eH. Acesso em: 22 nov. 2018.

LEHR, F.; OsBorn, J. A focus on comprehension. Honolulu: PREL - Pacific Resources for Education and Learning, 2005. Disponível em: https://bit.ly/2J3Mx9y. Acesso em: 17 dez. 2018

RÖSLER, D. Curricular interfaces: the interaction of language and contents at University level. ForumSprache, München, v. 2, n. 3, 2010, p. 10-15.

SCHMELTER, L. Entwicklungstendenzen und Desiderata der bilingualen achfachdidaktik. In: HALlet, W.; KöNIGS, F. G. Handbuch Bilingualer Unterricht. Content and language integrated learning. Seelze: Kallmeyer-Klett, 2013. p. 40-45.

SPINASSÉ, K. P. As interferências da Língua Materna e o aprendizado do Alemão como Língua Estrangeira por crianças bilíngues. Pandaemonium Germanicum, São Paulo, v. 10, 2006, p. 339-362.

SPINASSÉ, K. P. Deutsch als fremdsprache in Brasilien: eine studie über kontextabhängige unterschiedliche lernersprachen und muttersprachliche interferenzen. Berlin: Peter Lang, 2005.

Uphoff, D.; DeBIA, D. T. O papel do ensino de língua e a passagem para as disciplinas de literatura no curso de Letras-Alemão da USP: considerações a partir de uma análise de necessidades. In: UPHOFF, D. et al. (orgs.). O ensino de alemão em contexto universitário: modalidades, desafios e perspectivas. São Paulo: Humanitas, 2017. p. 169-190.

UphOFF, D; LOBATO, E. R. R.; SAFRA, M. F. A história do ensino de alemão no curso de Letras da Universidade de São Paulo. Revista HELB, Brasília, v. 8, n. 1, 2014. Disponível em: https://bit.ly/2J2RbEx. Acesso em: 19 nov. 2018.

VOLLMER, H. J. Das Verhältnis von sprach- und Inhaltslernen im Bilingualen unterricht. In: HALlET, W; KÖNIGS, F. G. Handbuch Bilingualer unterricht. Content and language integrated learning. Seelze: Kallmeyer-Klett, 2013. p. 124-131.

WÜRFFEl, N. Leseverstehen. In: OOMEN-Welke, I.; Ahrenholz, B. (Orgs.). Deutsch als Fremdsprache. Baltmannsweiler: Schneider Hohengehren, 2013, p. 130-141.

WÜRFFEL, N. Strategiengebrauch bei Aufgabenbearbeitungen in internetgestütztem Selbstlernmaterial. Tübingen: Gunter Narr, 2006. 